\title{
Designing for Dabblers and Deterring Drop-Outs in Citizen Science
}

\author{
Alexandra Eveleigh ${ }^{1}$, Charlene Jennett ${ }^{1}$, Ann Blandford ${ }^{1}$, Philip Brohan ${ }^{2}$, Anna L. Cox ${ }^{1}$ \\ ${ }^{1}$ UCL Interaction Centre, University College \\ London, London, UK, WC1E 6BT \\ alexandra.eveleigh.09, charlene.jennett, \\ ${ }^{2}$ Met Office Hadley Centre, \\ Exeter, UK \\ philip.brohan@metoffice.gov.uk
}

a.blandford, anna.cox@ucl.ac.uk

\begin{abstract}
In most online citizen science projects, a large proportion of participants contribute in small quantities. To investigate how low contributors differ from committed volunteers, we distributed a survey to members of the Old Weather project, followed by interviews with respondents selected according to a range of contribution levels. The studies reveal a complex relationship between motivations and contribution. Whilst high contributors were deeply engaged by social or competitive features, low contributors described a solitary experience of 'dabbling' in projects for short periods. Since the majority of participants exhibit this small-scale contribution pattern, there is great potential value in designing interfaces to tempt lone workers to complete 'just another page', or to lure early drop-outs back into participation. This includes breaking the work into components which can be tackled without a major commitment of time and effort, and providing feedback on the quality and value of these contributions.
\end{abstract}

\section{Author Keywords}

Citizen science; motivation; engagement; dabblers.

\section{ACM Classification Keywords}

H.1.2. User/Machine Systems: Human Factors.

\section{INTRODUCTION}

Citizen science involves scientists partnering with volunteers to assist with the research process, and is gaining in popularity due to the innovative use of web and mobile technologies [12]. Examples of online citizen science programmes span multiple disciplines and cross all points in the research workflow [22], including data collection (eBird), classification (Galaxy Zoo, Stardust@Home) and analysis (EyeWire, FoldIt), right through to the dissemination of research findings [e.g. 10]. Success is dependent upon the active participation of volunteers, hence a growing number of researchers are now investigating what prompts or sustains participants' involvement in citizen science $[19,21]$.

Permission to make digital or hard copies of part or all of this work for personal or classroom use is granted without fee provided that copies are not made or distributed for profit or commercial advantage and that copies bear this notice and the full citation on the first page. Copyrights for thirdparty components of this work must be honoured. For all other uses,

contact the Owner/Author.

Copyright is held by the owner/author(s).

CHI 2014, Apr 26 - May 01 2014, Toronto, ON, Canada

ACM 978-1-4503-2473-1/14/04.

http://dx.doi.org/10.1145/2556288.2557262
Whilst prior research has defined motivational success in citizen science in terms of sustained contribution [13, 15], we focus instead on the experiences of those majority of participants who contribute to the project in small quantities or in short bursts. Studying the experiences of participants who contribute fleetingly or intermittently may seem counter-intuitive. Drop-outs would appear to be indicative of a lack of motivation to continue participation; micro individual contributions might suggest that motivation to participate is weak or not prioritised against competing demands on volunteers' time. Yet the majority of those involved in citizen science will have precisely this experience of participation [14]. Where tasks can be completed by individuals working alone without being contingent upon the work of other participants, each person's input, however small, is valuable.

We begin by introducing Old Weather - a project that fits a characteristic skewed pattern of participation in citizen science: over the period covered by this study (October 2010 to July 2012), 94\% of participants contributed in aggregate $15 \%$ of project input. This is followed by a review of relevant literature which attests to a complex framework of motivational factors (and disincentives) that impact upon both intention to participate and actual contribution behaviour. Then we present two studies on participation in Old Weather: Study 1, a survey study, revealed several significant relationships between intrinsic motivation, extrinsic motivation, and contribution behaviour. Study 2, an interview study, revealed factors that led volunteers to 'dabble' and/or drop-out. We finish by presenting recommendations for designing for dabblers and deterring drop-outs.

\section{BACKGROUND}

\section{Old Weather}

Old Weather [23] was launched in 2010 as part of the Zooniverse, a consortium of virtual citizen science and humanities projects [19]. The primary task is to transcribe the weather observations recorded in historical ships' log books (see Fig. 1). Volunteers can also, optionally, transcribe additional 'event' information they deem important, such as battle action or personnel changes. Scientists use the weather data for climate modelling. The edited log books are of interest to both naval and family historians. 


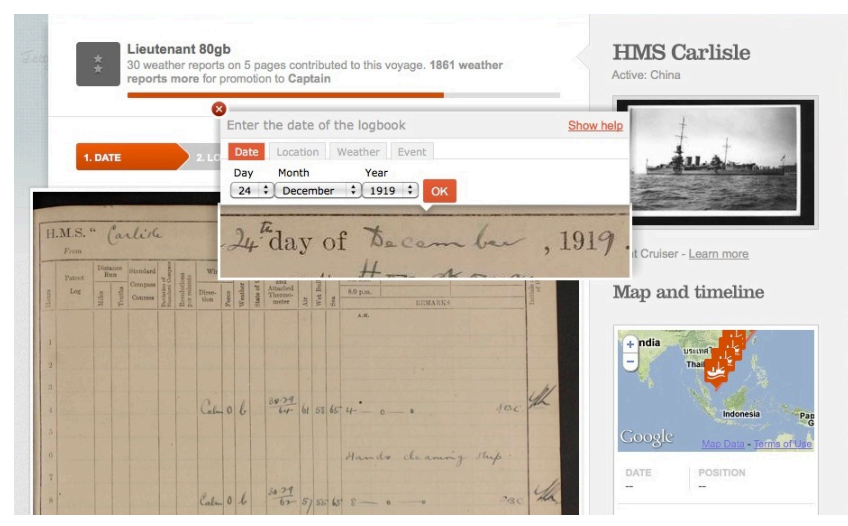

Figure 1. The Old Weather log book transcription interface.

Unusually, Old Weather can appeal to participants with scientific or historical interests (or both), and produces outputs useful for research in both fields [20]. Although participation in Old Weather is open to anyone who signs up, a ranking system recognizing the quantity of weather transcriptions made by each volunteer aims to motivate sustained and loyal participation through competition to become 'Captain' of each ship. A community forum is also provided where participants can post queries and discuss progress [20].

\section{Participation in Virtual Citizen Science}

Haythornthwaite [8] identifies two models of open collaboration operating on the Internet: a lightweight model based on small scale contributions from the widest possible pool of participants, and a heavyweight approach drawing upon traditions of volunteering and peer-review. At a conceptual level, Old Weather fits into the lightweight category. Wiggins and Crowston [22] suggest that in such circumstances, project sustainability results not so much from persistent and committed individual effort as from a ready supply of fresh participants.

Yet empirical research into participation in citizen science has largely proceeded under the assumption that 'sustained contribution by individual volunteers is critical for the viability of such communities' [13]. Researchers are aware that contributors often slow down or drop out of projects after an initial flurry of activity, and are troubled by this 'alarmingly high attrition rate' [14], but choose nevertheless to concentrate on encouraging in-depth, committed involvement rather than facilitating occasional participation. This jeopardizes not only project sustainability but also the scalability of citizen science: as the range of initiatives on offer continues to grow, projects cannot afford to rely upon intrinsically-motivated core groups of participants willing to devote considerable personal effort in every niche investigation $[7,11]$.

In part this focus on sustained participation has arisen because of the practical difficulties of recruiting research participants who are only briefly involved with a project, and the greater likelihood that committed participants will respond to surveys and interview invitations. This effect is likely to be magnified in those studies which draw samples only from current participants [2, 14], or use snowball recruitment techniques [21]. Elsewhere, as Nov et al. [13] observe, motivation is studied in isolation from actual contribution levels $[16,21]$.

There is variation in both quantity and depth of participation between committed 'super-volunteers' [5] and more casual visitors which is poorly reflected in existing studies of citizen science [6]. For example, only a small proportion ever participate in project forums [20]. This stratification of participation is acknowledged in Reed et al.'s [19] study of the Zooniverse, but the analysis does not differentiate between types of participant. Similarly, Raddick et al.'s recent study [17] of Galaxy Zoo recognises that deeper involvement, such as forum posting, may be driven by different motivations to small-scale contributions, but reserves this question for future research.

Considering that previous citizen science research tends to concentrate on sustained participation and the positive motivations of high contributors, one goal for our research was to uncover more about casual engagement and factors which discourage participation. Another aim was to investigate the extent to which intrinsic and extrinsic motivations influence both quality and quantity of contributions.

\section{Intrinsic and Extrinsic Motivations in Citizen Science} The sampling strategy used by Reed et al. [19] is underpinned by Crowston and Fagnot's [6] 'motivational arc' progression from non-participant to committed contributor. Crowston and Fagnot are careful to identify separate motives for each contribution level. They suggest that the initial motivation to contribute is a curiosity-driven exploration spurred by a combination of awareness, the volunteer's perceived capacity to complete the task, and an evaluation of the costs and benefits of contributing; a more complex motivational framework is only pertinent at sustained and meta contribution levels.

Comparing the results of empirical studies of motivation in citizen science is complicated because of the diversity of contributions [6] and because participants are typically motivated by more than one factor simultaneously [17, 19] and also due to the variety of different frameworks used to study motivation [19]. Motivators can be broadly divided into intrinsic (those which stem from the task itself) and extrinsic (the outcomes of an activity) [1]. In the context of Old Weather, examples of intrinsic factors include subject interest and curiosity, competence in the transcription task, and an enjoyment derived from taking part in the project. Several recent studies have underlined the importance of these intrinsic, often egoistic, factors to citizen science participants [14, 21], although any bias in survey samples towards more active, committed members may have affected these results since core participants are likely to have a high degree of intrinsic motivation [11]. Collective factors (defined as participants' identification with project 
goals, such as contributing towards solutions to climate change in the context of Old Weather) also perform strongly in existing research $[14,17]$.

Conversely, extrinsic community factors (motivation derived through interaction with other volunteers, e.g. status gained for expertise or high quality work) were rated at the bottom of a list of primary motives by Galaxy Zoo volunteers [17]; similarly, group norms and the reward motives of reputation and social interaction were found to be less important than intrinsic and collective motives to participants in Stardust@Home. Extrinsic rewards are nevertheless attracting increasing research attention, particularly in the context of 'gamification' and the search for motivational features which can be easily operationalized $[3,15]$ through competition and target-setting, or by providing a forum to encourage discussion and interaction around project tasks. Even so, the focus remains on sustaining rather than attracting participants [9].

\section{STUDY 1: ONLINE SURVEY}

The first aim of Study 1 was to investigate how intrinsic and extrinsic motivations affect both the quantity of contributions; and the depth of participation. We predicted that intrinsically motivated Old Weather participants are more likely to engage with the project in depth, whereas extrinsically motivated Old Weather participants will engage in the project in a more casual way and are unlikely to contribute anything more than the basic weather observation data. Our hypotheses were:

- H1: Intrinsic motivation is positively correlated with (a) total number of transcriptions, (b) transcribing nonmandated 'event' information from the ship' logs (in addition to the basic weather observations), and (c) total forum posts.

- H2: Extrinsic motivation is positively correlated with total number of transcriptions only.

The second aim of Study 1 was to explore differences between low contributors (Low C) and high contributors (High C). We hypothesised that:

- H3: High $\mathrm{C}$ will have more forum posts than Low $\mathrm{C}$ and will be more likely to transcribe event information.

- H4: High $\mathrm{C}$ will have higher intrinsic and extrinsic motivation scores compared to Low C.

\section{Method}

Design

Data was obtained from two sources - project records of contributions and an online survey. 'Total number of pages transcribed' and 'total forum posts' were obtained from the project records. 'Transcribing event information' came from a survey question to ask participants about this. Scores for 'intrinsic motivation' and 'extrinsic motivation' were also calculated from survey answers [1].

To investigate $H 3$ and $H 4$, we split our sample into three parts. 'Low C' had total transcriptions below the $33^{\text {rd }}$ percentile, and 'High $C$ ' had total transcriptions above the $66^{\text {th }}$ percentile.

\section{Participants}

In July 2012 we sent an invitation to the Old Weather forum and mailing list to take part in an online survey about the experiences of participating in the project (28347 registered users). We received 545 responses, or $1.92 \%$ of registered users; this underestimates the response rate, since we cannot tell exactly how many people received the invitation.

299 provided their Old Weather username and consented to us matching their survey responses with their project records. Therefore our study sample is 299 participants. The biggest participant age brackets were: $60-79$ years $(32.1 \%)$, 46-59 (26.8\%) and 26-35 (14.4\%). 161 were male (53.8\%), 131 female $(43.8 \%)$ and 7 preferred not to say $(2.3 \%)$. The majority were from the USA $(35 \%)$ and GB $(33 \%)$. Others were from Canada (5\%), The Netherlands (5\%), Australia $(4 \%)$, Germany (3\%), Italy (3\%) and 24 other countries.

\section{Online Survey}

The online survey ${ }^{1}$ was made available for 4 weeks. It comprised 16 questions covering participants' background, why they joined the project, and their motivations for taking part. It took approximately 15 minutes to fill in. No monetary reward was offered for completing the survey.

For our hypotheses, we draw upon data from two of the survey questions - Q4 and Q11.

Q4 asked "Do you ever transcribe additional 'event' information (i.e. beyond the basic weather observations required for climate research)? Or are you involved in editing ship' histories for Naval-History .Net?" Respondents were asked to select "Yes" or "No." If they selected "Yes", they were asked to provide more details (open text).

Q11 consists of 30 statements about motivations to participate in Old Weather. We created these statements by adapting the Work Preference Inventory [1], using a methodology similar to [2]. For example, questions included 'Curiosity is the driving force behind much of my participation in Old Weather' (intrinsic) and 'I am strongly motivated by becoming (and/or remaining) Captain of my ship on Old Weather' (extrinsic). The 30 items (15 intrinsic, 15 extrinsic) were presented in a random order and respondents were asked to rate their agreement on a 5 point scale, from $1=$ disagree strongly to $5=$ agree strongly. A sixth option 'Not applicable to me' (n.a.) was also provided, respecting a Zooniverse policy that volunteers should not be forced to answer questions [19]. Total scores for intrinsic and extrinsic motivations were calculated for each participant.

\footnotetext{
${ }^{1}$ www.ucl.ac.uk/uclic/people/c-jennett/tabs/ow-survey
} 


\section{Project records}

For the Old Weather usernames provided, we looked up the following data in the Old Weather project records:

- Total number of transcriptions (complete log book pages) submitted;

- Total number of days that transcriptions were submitted;

- Total number of forum posts.

\section{Results}

\section{Descriptive Statistics}

The number of transcriptions each person had completed ranged from 0 to 46417 , the mean being 1568 classifications $(\mathrm{SD}=4856.09)$, and the median number being 52 classifications. The distribution of contributions had a positive skew (see Figure 2). This pattern of contributions is typical of citizen science projects [14].

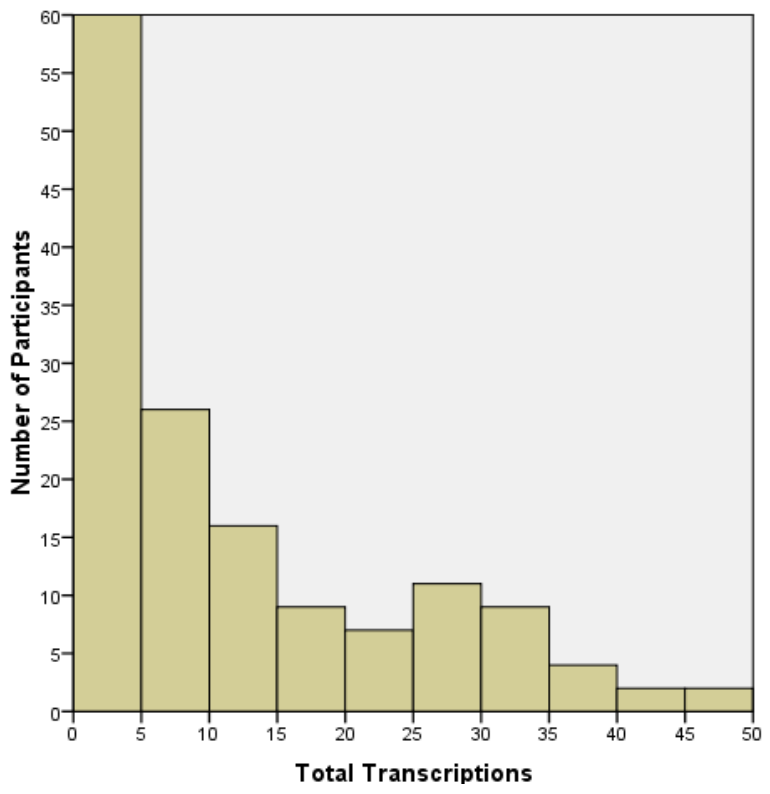

Figure 2. Histogram showing distribution of participants who completed fewer than 50 transcriptions $(\mathrm{N}=146)$.

A similar pattern can be seen in the number of days on which participants transcribed pages. This ranged from 0 to 616 days, the median being 7 days.

\section{Correlations}

There was a positive Spearman's Rank Order correlation between total transcriptions and total forum posts $\left(r_{\mathrm{s}(299)}=\right.$ $.568, p<.001)$. There were also several significant correlations between motivation scores, transcription behaviour and forum behaviour, see Table 1 .

\section{High Contributors versus Low Contributors}

Descriptive statistics were computed for Low $\mathrm{C}$ (those that had total transcriptions below the $33^{\text {rd }}$ percentile) and High C (above the $66^{\text {th }}$ percentile). High $C$ had 1000 times more total transcriptions than Low $\mathrm{C}$ (means of 4,607 and 3.95 respectively). High $\mathrm{C}$ were 6 times more likely to transcribe event information (75\% of High C replied "Yes" compared to $13 \%$ of Low $\mathrm{C}$ ). High $\mathrm{C}$ had 500 times more forum posts than Low C (means of 362 and 0.28 respectively). Statistical tests confirmed that these differences were highly significant $(p<.001)$.

\begin{tabular}{lllllll}
\hline & $\begin{array}{l}\text { Total } \\
\text { transcriptions }\end{array}$ & $\begin{array}{l}\text { Transcribing } \\
\text { event } \\
\text { information }\end{array}$ & $\begin{array}{l}\text { Total forum } \\
\text { posts }\end{array}$ & \\
\cline { 2 - 7 } & $r_{\mathrm{s}}$ & $P$ & $r_{\mathrm{s}}$ & $P$ & $r_{\mathrm{s}}$ & $p$ \\
\hline $\begin{array}{l}\text { Intrinsic } \\
\text { motivation } \\
(N=254)\end{array}$ & .220 & $<.001$ & .132 & .036 & .145 & .020 \\
\hline $\begin{array}{l}\text { Extrinsic } \\
\text { motivation } \\
(N=214)\end{array}$ & .201 & .003 & .001 & .989 & .099 & .147 \\
\hline
\end{tabular}

(Note that the Ns in Table 1 are lower than 299 because ' $n . a$.' responses were treated as missing data.)

Table 1. Spearman correlations for motivation scores and measures of contribution behaviour.

Intrinsic and extrinsic motivation scores were computed for Low $\mathrm{C}$ and High C, see Table 2. Independent sample $t$-tests revealed that High $\mathrm{C}$ scored significant higher than Low $\mathrm{C}$ for both intrinsic motivation $\left(t_{(160)}=-3.529, p=.001\right)$ and extrinsic motivation $\left(t_{(139)}=-3.198, p=.002\right)$.

\begin{tabular}{lll}
\hline & Low C & High C \\
\hline Intrinsic motivation & $(N=69)$ & $(N=93)$ \\
Range & 33 to 66 & 34 to 68 \\
Mean (SD) & $49.35(6.02)$ & $53.08(7.08)$ \\
\hline Extrinsic motivation & $(N=61)$ & $(N=80)$ \\
Range & 17 to 49 & 18 to 55 \\
Mean (SD) & $30.90(7.76)$ & $35.06(7.57)$ \\
\hline
\end{tabular}

(Again note that $N$ s exclude 'n.a.' responses).

Table 2. Descriptive statistics of intrinsic and extrinsic motivation scores, comparing Low $\mathrm{C}$ and High $\mathrm{C}$.

\section{Discussion}

$\mathrm{H} 1$ and H2 were supported: higher intrinsic motivation was associated with a greater number of contributions (total transcriptions) and greater depth of participation (transcribing event information, total forum posts); higher extrinsic motivation was associated only with greater number of contributions. In line with Haythornthwaite's theory [8], this suggests that intrinsically motivated volunteers are more likely to contribute in depth and form a core community on the project forum, whereas extrinsically motivated volunteers engage in the project in a more casual way. 
H3 was supported: High C posted over 500 forum posts on average, whereas Low $\mathrm{C}$ posted $<1$ on average. We also found a significant relationship between total transcriptions and total forum posts. These results are in line with Reed et al's [19] finding that social engagement - awareness and interaction with other members - is an important motivating factor for a core subgroup of volunteers. Also $81 \%$ of High $\mathrm{C}$ transcribed event information, compared to $31 \%$ of Low C. This suggests that High $\mathrm{C}$ do more detailed work, possibly aided by their greater experience in the project. Again this is in line with past research suggesting a preference for complex or varied tasks (over the straightforward or routine) amongst this subgroup of participants [19].

H4 was also supported: High C scored significantly higher than Low $\mathrm{C}$ for both intrinsic and extrinsic motivation. This suggests a relationship between motivation and contribution which few empirical studies have explored explicitly [13]. Whilst the experiences of highly motivated supervolunteers have received some research attention [5], there is still a lot that is unknown about the motivations and experiences of low contributors. This led us to conducting Study 2 to find out more about participants' motivations and experiences.

\section{STUDY 2: QUALITATIVE FOLLOW-UP}

Only a handful of studies have investigated casual participation in citizen science projects as of yet. One highlight of Rotman et al.'s [21] work is to show the dynamic nature of volunteers' motivations, even when the end goal remains constant. The authors identify two pivotal points: the initial decision to participate and subsequent resolution to continue, and argue that different motivations come into play at each stage. At an early stage, the motivation to participate may be only tangential curiosity. Later, participants are motivated to continue by a more complex framework of factors [6, 21]. Rotman et al. [21] also, unusually, present findings on obstacles to collaboration alongside positive motivations to contribute, identifying credibility and trust as critical issues. Barriers to participation are also discussed in Causer and Wallace's [5] evaluation of a humanities project whose manuscript transcription task is similar to Old Weather. Identified factors included a lack of time, feeling daunted by the task and worrying that a contribution might not reach expected quality standards.

In the context of environmental data crowdsourcing, Massung et al. [11] break new ground in investigating strategies to engage casual participants. Their finding that motivation alone was not enough to entice casual use of a data collection app, and the suggestion that contextual facilitators of participation (such as lifestyle) need to be considered alongside motivating factors, turns the time opportunity barrier on its head and could have important bearings on the design of citizen science platforms to appeal to a wider volunteer public.
Building upon this existing work, our goal was to investigate enablers and barriers for casual participation in Old Weather. In Study 2, we analysed the free text comments from the survey and conducted semi-structured interviews with a subset of Study 1 participants. We particularly considered:

- The participation experience: why, when and in what contexts do people participate?

- What are the factors that constrain time to participate?

- What are the reasons for dropping out of a project?

- Could non-active members be tempted back into participation in the future?

\section{Method}

Interviews

Potential interviewees were identified according to top and bottom scores on the intrinsic and extrinsic scales in the survey, and high and low contribution records. This crosssectional recruitment strategy aimed to ensure that the interviews covered a range of contribution levels and a mix of declared motivations. Invitations to participate were sent to respondents' email addresses registered with the Zooniverse. Of the 43 respondents contacted, 16 were interviewed and 1 sent a detailed email response. We achieved an approximate balance between low (9) and high (7) contributors. An individual may score highly for both intrinsic and extrinsic motivation simultaneously, or high on one scale and low on the other, or express moderately equal motivations on both scales. Our pool comprised: high extrinsic (4), low extrinsic (4), high intrinsic (3), low intrinsic (1), mixed declared motivations (4). The interviews took place via Skype. Interviews were audiorecorded and varied in length, from 30 minutes to 1 hour. All participants received a gift voucher for taking part.

\section{Thematic Analysis}

The interview transcripts (including the emailed response) were analysed using thematic analysis [4]. This involves coding interesting sections of the transcript in a consistent way, and subsequently grouping those codes into themes. Themes help to explain what the data means and relate it to the research questions. Free text comments submitted to the survey in Study 1 were also analysed alongside the interview transcripts using the same technique.

\section{Results}

Two strong groupings that developed through the thematic analysis were 'dabbling' and 'dropping-out'. The results reported here focus on these two themes. We noticed that several participants who had contributed a few hundred classifications described a similar low-commitment attitude to participation. These participants (whom we now term 'dabblers' and define according to their 'weak tie', intermittent approach to participation [8]) shared many characteristics with project drop-outs. 
Six interviewees had contributed no more than 50 transcriptions, 1 interviewee had not submitted a single page, and 3 others had records in single figures. 3 further participants had transcription records in the 200s, but described an occasional pattern of contributing to the project in short bursts; this brings the total number of interview participants we deem 'dabblers' to 9 .

We identified four main themes in relation to dabbling:

1. The experience of dabbling

2. Is dabbling a cause for concern?

3. Catalysts to dropping out

4. Long-term dabblers

To illustrate each theme, we provide quotes from the interview transcripts (denoted as I) and from survey comments (S). To provide further context, we also include the person's total number of transcriptions $(\mathrm{t})$.

\section{The Experience of Dabbling}

\section{Initial Engagement}

Since involvement begins with an initial contribution, it is important to consider what prompts (or proves a barrier to) initial participation, particularly since many more people will sign up than actually contribute [6]. Most interviewees described an initial process of exploration, of seeking a project which suited their interests and the time they had available. Like [21], we found that egoism, or personal interests, guided this initial contribution decision: What I do is, I just, like - when a new project comes up and it interests me - I'll go on it and I'll read, you know, how to do it, how to go, work through it... (I6 - 2 transcriptions)

This is the first manifestation of the activity we dub 'dabbling': I think you just try it out, do some classifications and then you stay or you move on. (I15 - 203t)

At this 'testing the waters' stage, dabblers may not exhibit much in the way of allegiance to a particular project: $I$ didn't really go into it as a regular commitment. I picked the ship that I picked, the Magnolia, just because that's one of my favourite trees.[...] So it wasn't that I set out that 'oh, I'm going to be the Captain of the Magnolia', it was more 'It's an interesting topic, it's something I can do easily, it doesn't require a huge amount of brain power although it does require attention'. (I13 - 50t)

Rather the decision to contribute is predicated on the dabbler's perceived ability to make a useful contribution, or capacity to fit in participation around other commitments: $I$ first just wanted to try it out and see whether I was able to cope with the tasks. Then I enjoyed it and depending on my other schedules I would try to do it regularly. (I15 - 203t)

Dabblers may be looking for nothing more than 'mindless entertainment' (I17 - 1t), or for a short-term activity which is purposeful but enjoyable - I thought I would just kind of do it occasionally, as kind of like something productive to do with my free time (I16 - 203t). This is a different initial mindset to that of the volunteer who is motivated by a preexisting commitment to the project's objectives - although super-contributors on one project might also be tempted to dabble elsewhere: I did dabble in a number of other Zooniverse projects - it's a question of finding what you have an aptitude for. (I3 - 22389t)

For many participants, this dabbling mode will be their only experience of a particular citizen science project, although a small proportion of dabblers go on to become longer-term contributors to a specific project: I try out every new Zooniverse project and then see how much I like it. To my surprise I liked it very much and I stayed on. (S - 15120t)

Even those who decide that a particular project is not for them may spend some time on this initial evaluation: $I$ poked around on it for a little bit, like for a couple of days or a day. And really it was a couple of things, it was a lot of typing, whereas a lot of other Zooniverse projects are kind of point and click, which is a little easier to do... (I17 - 1t)

\section{Working Alone}

In contrast to the collective (community or competitive) experience of citizen science that has been the focus of most research to date $[9,14,21]$, we found that dabblers mostly described a solitary experience. As one supercontributor explained, many participants are '...just happy clicking on their own' (I1 - 15120t). This was often true irrespective of contribution level, but lone working was something which had a positive value for participants whose contributions were intermittent: I have only occasional opportunities to enjoy time on Old Weather, but it can be a delightful escape. I choose not to use its interactive features because this is one of the places I go for me time. $(\mathrm{S}-9 \mathrm{t})$

In line with Crowston and Fagnot's prediction [6], dabblers showed little sign of obligation towards a group enterprise. One interviewee associated this directly to the prescribed nature of the transcription task: It wasn't like [...] we would talk about it at work the next morning. So in terms of onsite participation with other people doing it, not a motivator, never factored in. Partially because it's not...it's very mechanical. (I13 - 50t)

\section{Is Dabbling a Cause for Concern?}

\section{The Invisible Value of Non-Active Participation}

Although the asymmetric, directed nature of citizen science sets it apart from the 'information commons' collaborations which are the focus of Crowston and Fagnot's discussion [6], a similar justification can be found for dabbling as for free riders: that dabblers can provide both an audience and evidence of current activity on the project. Both of these help raise the visibility of the project, as a citizen science initiative (aiding the engagement of fresh volunteers) and of the scientific research itself (increasing its impact and recruiting advocates for the cause). 
Although it is likely that self-selection bias in our sample over-represents dabblers with a continuing interest in Old Weather, it was striking that several interviewees spoke eloquently about the importance of the climate research outcomes of the project, even though they had themselves stopped contributing: I mean, I get all the emails, you know, so I'll read them and see, you know, what has Old Weather's community discovered thus far [...] the community, as it is, is contributing to science. (I17 - 1t)

Here then is a largely unrecognised audience for scientific research, made up of people who 'feel a deep connection with the project, having contributed'. (I5 - 260t). An ongoing connection with the project was clearly valued by certain dabblers, who saw themselves more as passive or resting members of the Old Weather community than detached or uninvolved: I wait for emails. It's a little more passive, because I have so many things grabbing my attention, and I assume I'm not alone in that. [...] You asked how could you encourage me to participate more, and the answer is continue to send me emails. (I12 - 2t)

Lapsed participants sought communications from the scientists involved with the project, partly as acknowledgement for their contribution, however small: ...after we've done our contribution, whether it's a one-time contribution or an ongoing contribution [...] maybe an email saying, you know, just one or two major papers have been published and they are on these conference sites, or The New York Times has referenced our project... (I5 - 260t)

But also, significantly for project designers, as a potential lifeline tempting them back into active participation: I'm still registered. I hope, and I would like to contribute something in the near future. (I5 - 260t)

\section{Positive Participant Turnover}

Online citizen science is in any case not particularly about completing the tasks with the fewest (or least expensive) participants, as might be the case where contributors were receiving financial compensation. Rather the focus is upon achieving the work quickly, but also with the greatest possible accuracy. Seen in this light, there are certain advantages to accepting - even promoting - a high turnover of participants: firstly, on 'the many eyes' principle that mistakes are easier to spot when multiple people review the work [18]: And that was one of the things in Old Weather too that was nice, going 'this looks like a 7 to me, but it might be a 1', but there's going to be a lot of eyes on this. So the anxiety level wasn't very high about getting things wrong. Obviously I was trying to be accurate, but it was nice knowing there was back-up. (I13 - 256t); and secondly, as a necessary mechanism to mitigate errors caused by individuals getting bored by the often rather mundane or repetitious tasks: Then getting into a rhythm, you start to go on auto-pilot and that's a bad habit. (I5 - 260t)

\section{Catalysts to Dropping-Out}

Rather than focusing exclusively on what factors motivate participation, which, as [15] observe, can often be difficult to operationalize, an alternative approach is to consider what factors contribute to people dropping out of a project.

Our analysis revealed a concern about the usefulness of contributions which was associated with dropping-out of the project at an early stage: I lost motivation to continue contributing information because I was not sure how useful my input was. I did not want to take challenging pages if I would not be producing useful results and I had no way to see how useful my previous contributions were. $(\mathrm{S}-122 \mathrm{t})$

A commitment to producing 'real research' so that participants can know they are not wasting their time is one of the fundamental principles upon which all the Zooniverse projects are founded [24]. What is striking here was the concern shown in reverse by dabblers towards providing accurate information for scientific research, even before they had established a personal commitment to the citizen science project: I really like the concept but I had trouble deciphering the handwriting. So I was afraid I was getting things wrong and if there were ones that I could be sure I was doing right then I would love to keep doing it, but I was afraid of screwing it up. (I11 - 0t)

Boredom with the task is another major factor behind dropouts: It was probably just the...I guess the monotony of just, like...it's a pretty basic task, so I guess after a point, you might get bored. (I15 - 203t). Given the form-filling quality of the basic transcription task, it is inevitable that many participants - those who find no intrinsic interest in the subject content, or who contribute too spasmodically to get enthused - begin to find 'It just felt like tedious work.' (S 38t): I got into it for a while, and then, I'm not sure if I just... I guess I kind of lost interest. (I15 - 203t)

Even where interviewees found the work interesting, there was an opportunity cost associated with contributing: I think it's intrinsically interesting. Again the reason I quit wasn't that you weren't maintaining my interest enough. It was just that I... I was doing too many other things in life, I just didn't find time for it. (I14 - 256t)

\section{Long-Term Dabblers}

A second definition of 'dabbling' relates to small-scale, but intermittent, participation over an extended period of time: And I liked the fact that, you know, it was just, at my leisure and I could do it when I wanted to, and it was like not structured, I can just go in, do it and then, you know, stop when I wanted to, and then go back and pick up whenever I needed to. (I6 - 2t)

Again, this is a pattern which tends to be repeated across several different citizen science initiatives, with no clear commitment being shown to any particular project: I think I'm still participating in Planet Hunters, Galaxy Zoo... Well, it depends a bit on my free time. So I did some work on Ancient Lives. I tried out the Whale project. Yeah, so it depends a bit. For example, the Whale project is not really 
convenient when I'm at university, the sound files. But for example, Planet Hunters works fine. (I15 - 203t)

The key may lie in understanding the casual nature of dabblers' contribution pattern, and how participation in citizen science fits around their day-to-day life rather than being an activity for which they make time specifically: $O h$ just like in the evening, you know for an hour or two before I went to bed or something, you know at home, something like that. And not every day, only on days when I had time. It was a pretty informal thing, yeah. (I16 - 15t)

There was also a strong seasonal shape to volunteers' contributions. Many survey respondents mentioned that their participation increased in the winter when they were more likely to be spending time indoors: Old Weather is/was a great activity for me during snowy days, so my participation is sporadic. (S)

In contrast, three of the interviewees suggested that a burst of participation could only be achieved when job commitments were light or they were on holiday: I found I just didn't have the time [...] I felt I should do one major contribution. When I saw that I had the time, I actually was on holiday. (I5 - 260t)

\section{DISCUSSION: DESIGNING FOR DABBLING}

'Dabbling' is a term used by participants themselves to describe small-scale contribution to citizen science. As a result of our research, we have come to define dabbling as a curiosity-driven behaviour, occurring intermittently, fitting around other activities in participants' daily lives. Whilst some contributors dabble in just one project, more commonly dabbling involves dipping in and out of several different citizen science initiatives, with participants seeking variety, diversion, and amusement. Some micro contributors will make a brisk decision not to continue participation, becoming project drop-outs. Long-term dabblers in contrast retain a passive interest in the project and may re-kindle their active involvement at a later date.

Motivation is generally studied in citizen science with a view to encouraging and sustaining contributions towards the specified project task(s) $[13,22]$. One challenge then is to consider how to entice dabblers to make further contributions. Crowston and Fagnot [6] observe, few of the personal rewards of sustained contribution 'seem likely to apply to an initial contributor who is not familiar with the project or with other contributors', and the same is true of occasional dabbling participants. On the other hand, our results also suggest that there are some latent benefits to dabbling, which the focus on sustained contribution has overlooked. Supporting dabbling behaviour in citizen science can help to widen the impact of the underlying research, by raising awareness of scientific research problems and promoting scientific working methods and values. Encouraging participant turnover boosts the impression of an active, engaged community, which is not only important for the ongoing recruitment of volunteers but may also help to promote greater accuracy in project task completion (e.g. the 'many eyes' principle): the small amount each individual contributes is offset by the concern that dabblers exhibit for accuracy. Therefore, instead of trying to encourage a regular commitment from volunteers, an alternative approach is to encourage long-term dabbling - a kind of 'irregular' commitment, where it is made easy for volunteers to participate on and off at irregular intervals.

We highlight five design considerations which facilitate these dabbling behaviours in Old Weather. Other citizen science projects should consider adopting similar design features in order to capitalize fully on a wide-reaching but generalized intrinsic goodwill towards science, but without forcing individuals into a sustained commitment:

Facilitate independent working and participant choice most dabbling contributions are made by participants working alone, by volunteers who are not motivated by interacting with their peers, either collaboratively on a project forum, or through competition. Citizen science projects can still facilitate this independent working by enabling contributors to make their own choices about what they wish to work on and their level of participation, and track their personal progress. For instance, on Old Weather this might entail offering transcription choices according to the ship's location, or time period, or enabling participants to read or catch up on other volunteers' transcripts relevant to their personal affiliation to a particular ship. Projects might also introduce clearly graduated task difficulty levels, and tools to enable personal target-setting and progress monitoring. This might encourage an extended, if not indefinite, commitment towards a personally-set goal.

Optimize tasks to fit within busy lives - breaking tasks down into smaller-scale assignments enables occasional participation, taking account of short attention spans and busy schedules: the attention span on the Internet is I think more limited than in other areas of daily life, so I think if it takes you more than 5, 10, 15 minutes to complete a certain task, then it's just not interesting to a lot of people. And if you have no possibility to come back and to complete it later (I15 - 203c). Like Rotman et al. [21], we also suggest that smaller scale building blocks might also encourage new volunteers to overcome any anxiety over contributing to scientific research. Where tasks cannot be atomized further (the basic Old Weather transcription task, for instance, would be nonsensical if divided into smaller sections), they can still be optimized for dabblers in other ways. e.g., by enabling participants to return to complete a task for a limited period, or to complete it offline and upload it later, or by ensuring mobile and tablet device compatibility: I think if it was iPad compatible that would be a big help, just because it's not something that you have to do for hours at a time, it's something you can do in little spurts and maybe you can do it, you know, when you're sitting and waiting for the dentist (I17 - 1c).

Publicise scientific outcomes - do not assume that non- 
active participants have lost all interest. Many dabblers express an ongoing but passive interest in a project's progress, particularly in the scientific outcomes based on citizen participation. Dabblers are unlikely to seek out news proactively, but maintain their registration with a project deliberately in order to receive updates. For some dabblers, receiving the latest project email bulletin might be the catalyst which re-kindles their interest and spurs them back into active participation. Others will remain a passive but engaged audience for science, and a potential source of advocacy for the citizen science project.

Sell citizen science snacks, not gourmet meals! - this is clearly related to the idea of providing granular-sized tasks, but refers more specifically to the mechanisms used to keep people interested and engaged. Alongside encouraging prolonged, committed engagement through community forums or competitive games, projects can tempt more casual participants to increase their contributions gradually by smaller degrees. For instance, automatically bringing up a new task as soon as a completed one is submitted could encourage volunteers to think oh, I can get one more done before I go to bed, alright, I'll do one more (I13 - 50c). Other suggestions from dabblers for retaining or reinvigorating their interest included: special prize draws or scheduled challenges, and pushing periodic updates on project progress and scientific outcomes.

Enable personalized feedback to affirm quality - droppingout of participation is strongly associated with an anxiety about the quality of contribution. Our research suggests that volunteers are more likely to continue in participation if they believe their accuracy to be high - even if the task itself is not that interesting: I have tried most of the Zooniverse projects. On a couple I didn't feel that I was doing a good job (and didn't enjoy that feeling!), so I soon stopped. On others, I felt that I was doing something useful, so I continued to work on them even if it wasn't that interesting. (S). Citizen science projects could help to deter drop-outs by providing the means for volunteers to gain confidence in their own quality of contribution and learn how to improve. Possible mechanisms include: a flagging mechanism where participants are not confident of their input; sample task self-assessment tests (not necessarily as a preliminary to participation, since this would itself be a barrier to more casual contributions, although this is a possibility where a high premium is put on the accuracy of the data generated); or opening up the data checking process to the participants themselves. For example, an interface displaying any non-matching input from three or more participants transcribing independently, and offering a fourth participant the opportunity to judge the correct answer, possibly awarding points to fellow contributors based upon their accuracy level.

\section{Limitations and Future Work}

The response rate to the survey was $1.92 \%$ and only 299 participants provided their Old Weather username so that their contribution data could be matched to their survey responses. Although the response rate was low, the absolute sample size is comparable to other studies [14, 19, 21]. There is a likelihood of self-selection bias in Study 2, in that non-active participants with an ongoing interest in the project may have featured more strongly in our data pool than those who had lost all interest. But this does not make their perspective invalid. We suggest that our targeted approach of inviting participants to interview based upon their contributions and motivation scores enabled us to highlight the perspective of a category of volunteers who are overlooked by the usual snowball recruitment strategies. Also, this research focuses upon a single citizen science project. In future work it will be important to validate our findings by checking how they generalise to other virtual citizen science projects that involve different tasks and a different population of users.

\section{CONCLUSION}

Citizen science projects benefit from work by volunteers with varying levels of commitment: A typical project will have a few committed and productive super-volunteers, a much larger numbers of 'dabblers' (who contribute only occasionally), and even more 'drop-outs' (who tried the work, gave up, but remain interested). Previous research has concentrated on the super-volunteers, but a successful project must pay attention to the needs of all three groups.

A survey of participants in the Old Weather project allowed us to investigate the relationship between various measures of contribution and motivating factors. Both intrinsic (deriving from the task itself) and extrinsic motivations (deriving from the results of the task) were related to contribution behaviour in Old Weather, with highly motivated participants contributing more. But only intrinsic motivation was linked to broader contributions to the project, such as making more forum contributions and transcribing the optional non-weather information.

A series of interviews with selected project participants gave us further insight into the experiences of low contributors (dabblers). Some dabblers will inevitably drop out of a project, losing interest completely. However there are others who consider themselves to be 'non-active' members of the project, still interested in reading about the project and serving as advocates. A further kind of dabbler chooses to dabble in and out long-term, participating during less busy times of the year.

Dabblers represent a major part of citizen science projects, yet their perspective is often overlooked. The inclination of most prior research has been to encourage participants to behave like scientists in terms of building a sustained commitment to a specific project [7, 22]. Contrary to this view, we argue that projects should be designed to encourage dabbling as well as commitment. Our studies reveal that dabblers might be less motivated compared to super contributors, but they are still motivated. They were found to care about the progress of the project and the 
quality of the work they submit. As the majority of participants exhibit this small-scale contribution pattern, there is great potential value in designing interfaces to tempt lone workers to complete 'just another page', or to lure early drop-outs back into participation. We propose several design recommendations, such as breaking the work into components which can be tackled without a major commitment of time and effort, and providing feedback on the quality and value of these contributions. Instead of trying to design projects that encourage all volunteers to become more committed (e.g. increasing more social components), we argue for the importance of designing projects that make dabbling easier and help dabblers to feel that their contribution is valuable and valued.

\section{ACKNOWLEDGMENTS}

Thanks to Kathleen Mathieu, Paul Cairns, Zooniverse and the Old Weather science team, and the Old Weather volunteers. This research was partly funded by the EU project Citizen Cyberlab (Grant No 317705). Alexandra Eveleigh is supported by a UCL Graduate Research Scholarship for Cross Disciplinary Training.

\section{REFERENCES}

1. Amabile, T.M., Hill, K.G., Hennessey, B.A., and Tighe, E.M. The Work Preference Inventory: Assessing intrinsic and extrinsic motivational orientations. Journal of Personality and Social Psychology 66(5) (1994), 950.

2. Borst, W.A.M. Understanding Crowdsourcing: Effects of motivation and rewards on participation and performance in voluntary online activities (2010). hdl.handle.net/1765/1.

3. Bowser, A., Hansen, D., and Preece, J. Gamifying Citizen Science: Lessons and Future Directions. Workshop on Designing Gamification: Creating Gameful and Playful Experiences (2013).

4. Braun, V. and Clarke, V. Using thematic analysis in psychology. Qualitative research in psychology 3(2) (2006), 77-101.

5. Causer, T. and Wallace, V. Building A Volunteer Community: Results and Findings from Transcribe Bentham. Digital Humanities Quarterly 6(2) (2012).

6. Crowston, K. and Fagnot, I. The motivational arc of massive virtual collaboration. Proc IFIP WG 9.5 Working Conference on Virtuality and Society: Massive Virtual Communities (2008).

7. Crowston, K. and Prestopnik, N.R. Motivation and data quality in a citizen science game: A design science evaluation. Proc HICSS (2013), 450-459.

8. Haythornthwaite, C. Crowds and Communities: Light and Heavyweight Models of Peer Production. Proc HICSS (2009), 1-10.

9. Iacovides, I., Jennett, C., Cornish-Trestrail, C., and Cox, A.L. Do games attract or sustain engagement in citizen science?: a study of volunteer motivations. CHI Ext. Abstr. (2013), 1101-1106.

10.Lintott, C., Schawinski, K., Keel, W., et al. Galaxy Zoo: 'Hanny's Voorwerp', a quasar light echo? (2009). arxiv .org/abs/0906.5304.

11.Massung, E., Coyle, D., Cater, K.F., Jay, M., and Preist, C. Using crowdsourcing to support pro-environmental community activism. Proc CHI (2013), 371-380.

12.Newman, G., Wiggins, A., Crall, A., Graham, E., Newman, S., and Crowston, K. The future of citizen science: emerging technologies and shifting paradigms. Frontiers in Ecology and the Environment 10(6) (2012), 298-304.

13. Nov, O., Arazy, O., and Anderson, D. TechnologyMediated Citizen Science Participation: A Motivational Model. Proc ICWSM (2011).

14.Nov, O., Arazy, O., and Anderson, D. Dusting for science: motivation and participation of digital citizen science volunteers. Proc iConference (2011), 68-74.

15.Prestopnik, N.R. and Crowston, K. Gaming for (Citizen) Science: Exploring Motivation and Data Quality in the Context of Crowdsourced Science through the Design and Evaluation of a Social-Computational System. Proc eScienceW (2011), 28-33.

16.Raddick, M.J., Bracey, G., Gay, P.L., et al. Galaxy Zoo: Exploring the Motivations of Citizen Science Volunteers. Astronomy Education Review 9(1) (2010), 010103.

17.Raddick, M.J., Bracey, G., Gay, P.L., et al. Galaxy Zoo: Motivations of Citizen Scientists. arXiv preprint (2013) arXiv:1303.6886.

18. Raymond, E.S. The Cathedral and the Bazaar. First Monday 3(3) (1998).

19.Reed, J., Raddick, M.J., Lardner, A., and Carney, K. An Exploratory Factor Analysis of Motivations for Participating in Zooniverse, a Collection of Virtual Citizen Science Projects. Proc HICSS (2013), 610-619.

20.Romeo, F. and Blaser, L. Bringing Citizen Scientists and Historians Together. Proc Museums and the Web (2011).

21.Rotman, D., Preece, J., Hammock, J., et al. Dynamic changes in motivation in collaborative citizen-science projects. Proc CSCW (2012), 217-226.

22. Wiggins, A. and Crowston, K. Developing a conceptual model of virtual organisations for citizen science. International Journal of Organisational Design and Engineering 1(1) (2010), 148-162.

23.Zooniverse: Old Weather - Our Weather's Past, the Climate's Future. www.oldweather.org/.

24.Zooniverse: Purpose. www.zooniverse.org/about. 